\title{
Frequency Control System for a Synchronized Asynchronous Electric Drive
}

\author{
Victor N. Meshcheryakov ${ }^{1, *}$, and Dmitry S. Sibirtsev ${ }^{1}$, and Elena Gracheva $^{2}$ \\ ${ }^{1}$ Lipetsk State Technical University, Department of Electric Drives, Lipetsk, Russia \\ ${ }^{2}$ Kazan State Power Engineering University, str. Krasnoselskaya, 51, 420066, Kazan, Russia
}

\begin{abstract}
Considering the problem of energy saving at industrial enterprises, attention should be paid to the fact that about $70 \ldots 80 \%$ of all electric motors are asynchronous, and most of them are installed in unregulated drives. Most of these electric drives are equipped with asynchronous electric motors with a squirrel-cage rotor (AM SC). Energy saving problem in such cases can be solved by using a frequency converter (FC), however, all FC models are intended for AM SCs, while until the mid-90s the most common variable $\mathrm{AC}$ drives were electric drives equipped by an asynchronous motor with a phase rotor (AD PR) as they provided easy speed regulation through the rotor circuit. Such drives are usually used in hoisting and transport machines (conveyors, cranes, etc.). Direct transfer of the abovementioned drives to frequency-controlled mode is quite complicated due to the fact that standard inverters are designed to work with AM SCs having no phase rotor winding, and whose short-circuiting leads to additional electromagnetic losses in comparison with AM SC. An upcoming engineering trend is the development and research of synchronized AM control systems.
\end{abstract}

\section{Introduction}

The relevance of the study is determined by the following capabilities of synchronized machines [1,2]:

1) shunt characteristics;

2) reduction in electricity consumption;

3) easy speed maintaining in deep control mode.

The advantage of a synchronized asynchronous electric drive is that a precise speed maintaining does not require a complex computer and the use of speed sensors on the motor shaft. Apart from this, a synchronized asynchronous electric drive allows improving the energy characteristics and increasing the overload capacity, compared to an electric drive based on an AM SC [3].

When implementing synchronous frequency start with the rotor powered from the DC link of the current inverter, no additional starting power elements on the stator or rotor side are required, only the control system of the FC changes in relation to the control circuit for static modes. Therefore, along with the advantages, synchronous frequency start requires a more complex auto control system [4,5].

The synchronous mode of the motor has among others one advantage over the asynchronous mode which is the ability of the motor to change the magnitude and mark of the reactive power when adjusting the magnitude of the excitation current [6]. With direct connection of the stator winding to the supply mains providing motor overexcitation, reactive power is supplied to the supply mains network and, if underexcited, is consumed from the network, there is therefore a fundamental possibility of influencing the energy exchange process between the motor and the power supply system by controlling the excitation current of powerful synchronized asynchronous motors $[7,8]$.

\section{Approaches}

A wound-rotor induction motor operating in synchronous mode requires an accurate setting of the acceleration rate with its correction when the moment of inertia of the mechanism changes to ensure stable operation in the start-up mode carried out with a powerup sensor [9]. Therefore, an additional internal stator current control circuit subject to the motor speed control circuit is introduced into the automatic control system of a synchronized electric drive built on a current inverter to increase the stability. The internal circuits for regulating phase currents of the stator are based on a relay current controller. The block diagram of the frequency synchronized asynchronous electric drive is shown in Fig. 1.

The system of the frequency-controlled synchronized asynchronous electric drive uses a standard converter that feeds the stator winding. It contains an uncontrolled rectifier, the output of which is connected to the input of a controlled autonomous inverter.

The electromagnetic field produced by the stator winding is determined by the output parameters of the frequency converter: the current I1 and the frequency $\mathrm{f} 1$. The device contains a rectifier 1 and an inverter 2 , an

\footnotetext{
* Corresponding author: mesherek@stu.lipetsk.ru
} 


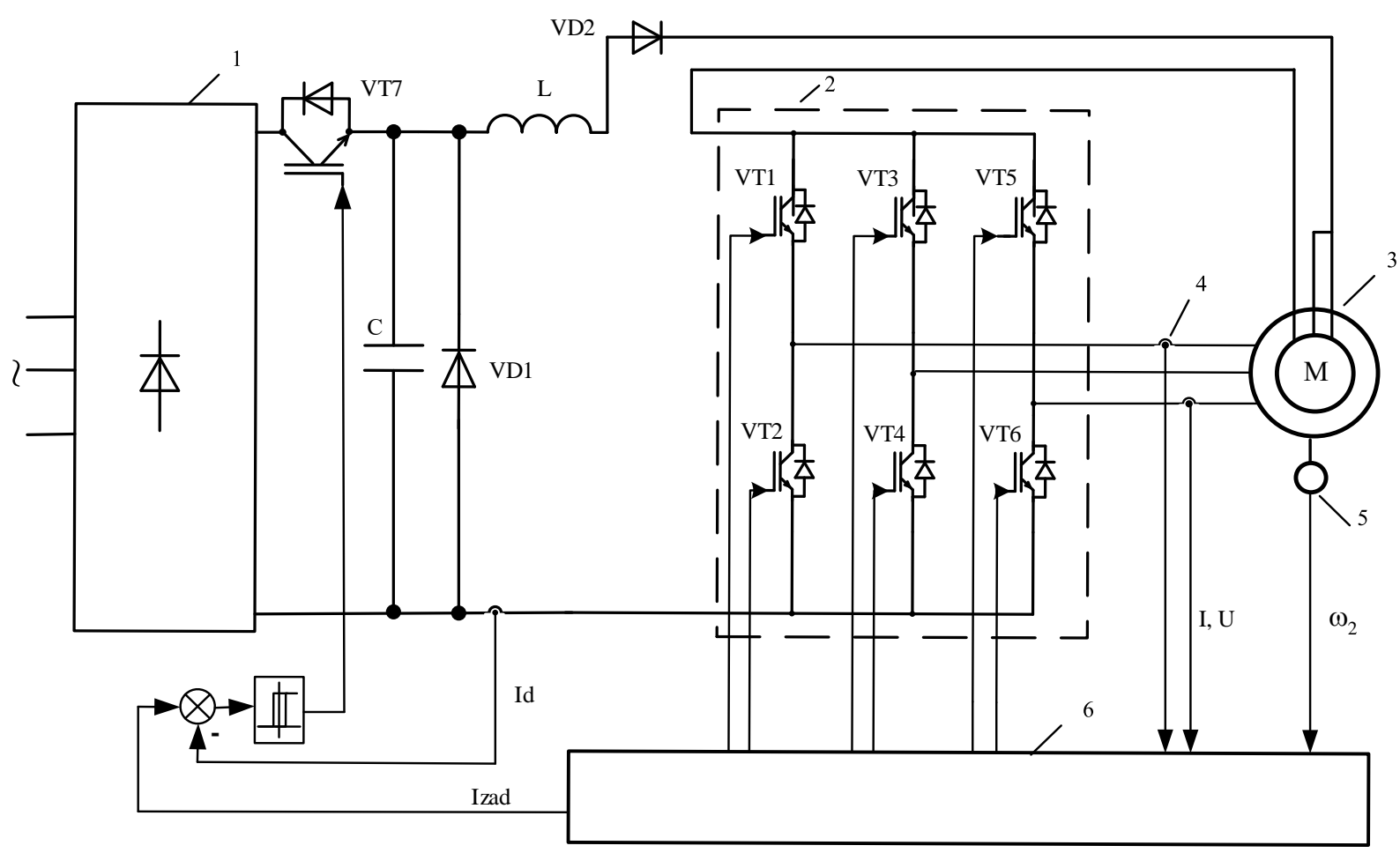

Fig. 1. Connection diagram of the synchronized motor.

electric motor 3 . The inverter is made on fully controlled valves - IGBT-transistors. The speed sensor 5 is mounted on the motor shaft, the sensors 4 supply the voltage and current signals to the control system 6 .

The stator current frequency is generated using the power-up sensor in the start-up mode. When reaching the given stator current frequency, the control system switches to the operating mode at the required speed. The current regulator operates according to the relay control. As a result of the comparison, we get the difference between the given and the actual values of the current in phases at the adders outputs [10,11]. The received signals are sent to the hysteresis inputs operating according to the following algorithm:

- when reaching the difference between the phase current set value and the phase current measured value of the threshold upper limit, the upper-arm valve is switched on and the lower-arm valve of the corresponding phase is switched off;

- when reaching the difference between the phase current set value and the phase current measured value of the threshold lower limit, the upper-arm valve is switched off and the lower-arm valve of the corresponding phase is switched on $[12,13]$.

Then the signal from the hysteresis output is fed to the output of the transistors control of the corresponding phase. The switching frequency of power transistors can be $10 \mathrm{kHz}$ [14].

Since the system generates only instantaneous values of the current moduli, and the instantaneous value of the stator voltage may differ from the set value due to external disturbances, the stability of the system is determined not by the value of the load angle $\theta$, but by the nature of the system's response to external disturbances. The stability criterion here is the same as for a conventional implicit-pole synchronous machine: with a load surge, the motor torque must increase, compensating for the load torque, in this case the mode is considered stable [15-17].

Drawing up a vector diagram to analyze the operating modes of the synchronized electric drive system (Figure 1), we fix the position of the stator current vector and direct it along the vertical axis [18]. The system automatically generates the moduli of the stator and rotor currents according to the motion equation, while the motor torque is proportional to the area of the triangle formed by the stator current, rotor current and magnetizing current.

By the cosine theorem, the area of a triangle formed by two vectors is maximal if the angle between them is 90 degrees. In the motor a load surge or load shedding primarily leads to rotation of the rotor current vector relative to the fixed stator current vector: with a surge, the angle between them decreases, and with a drop it increases [19]. From the abovesaid we can conclude as follows: with constant I1 and I 2 values, the synchronized asynchronous machine will be stable only in modes when the angle between them is greater or equal to 90 degrees. 


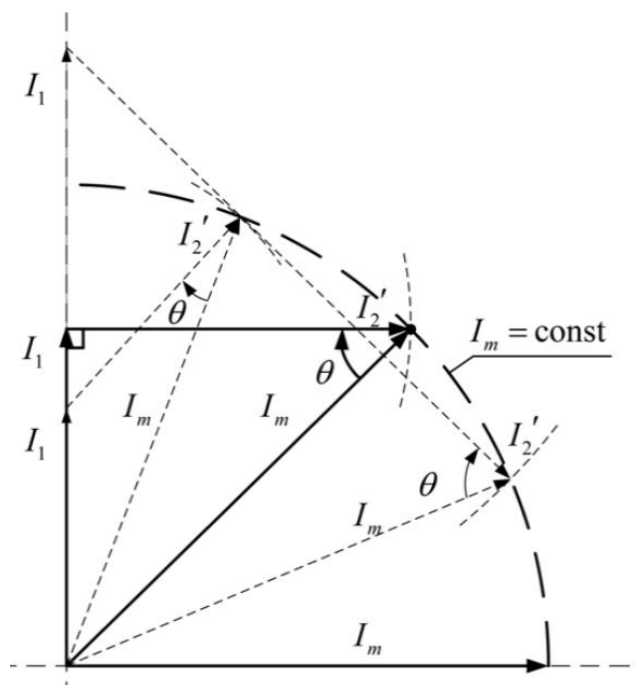

Fig. 2. Vector diagram to analyze the operating modes of the synchronized electric drive system.

The torque angle control circuit operates in the control system, which corrects the stator current frequency setting signal to reduce the rotor oscillations arising during the motor start-up. Adjustment of the torque angle control circuit is made considering the following features:

- the oscillation amplitude of the torque angle depends both on the electrical and mechanical parameters of the motor;
- static load on the drive shaft is determined by the average torque angle for the period of free oscillations [20];

- to quench the oscillations arising in the drive, according to classical mechanics, it is necessary to apply the control action in one phase with the oscillations of the system. The adjusting factor is chosen out of necessity to adjust the torque angle rapidly.

The factor is set to less than unity to have a stable system, but increasing it, the operating speed of the torque angle control circuit increases. Hence, it is practical to determine it independently for each separate electric drive. The time constant $\mathrm{T}$ is determined by the free oscillations frequency of the electric drive system, it should not be less than this frequency. Excessive increase leads to a degradation in the system dynamic characteristics when the load on the shaft changes.

\section{Result}

The proposed control system was modeled in the Matlab Simulink software environment (Fig. 3) [21]. The results of the simulation are shown in Fig. 4.

\section{Conclusions}

The synchronous asynchronous electric drive control system is designed and simulated in the work. Since the stability of the considered electric drive is greatly

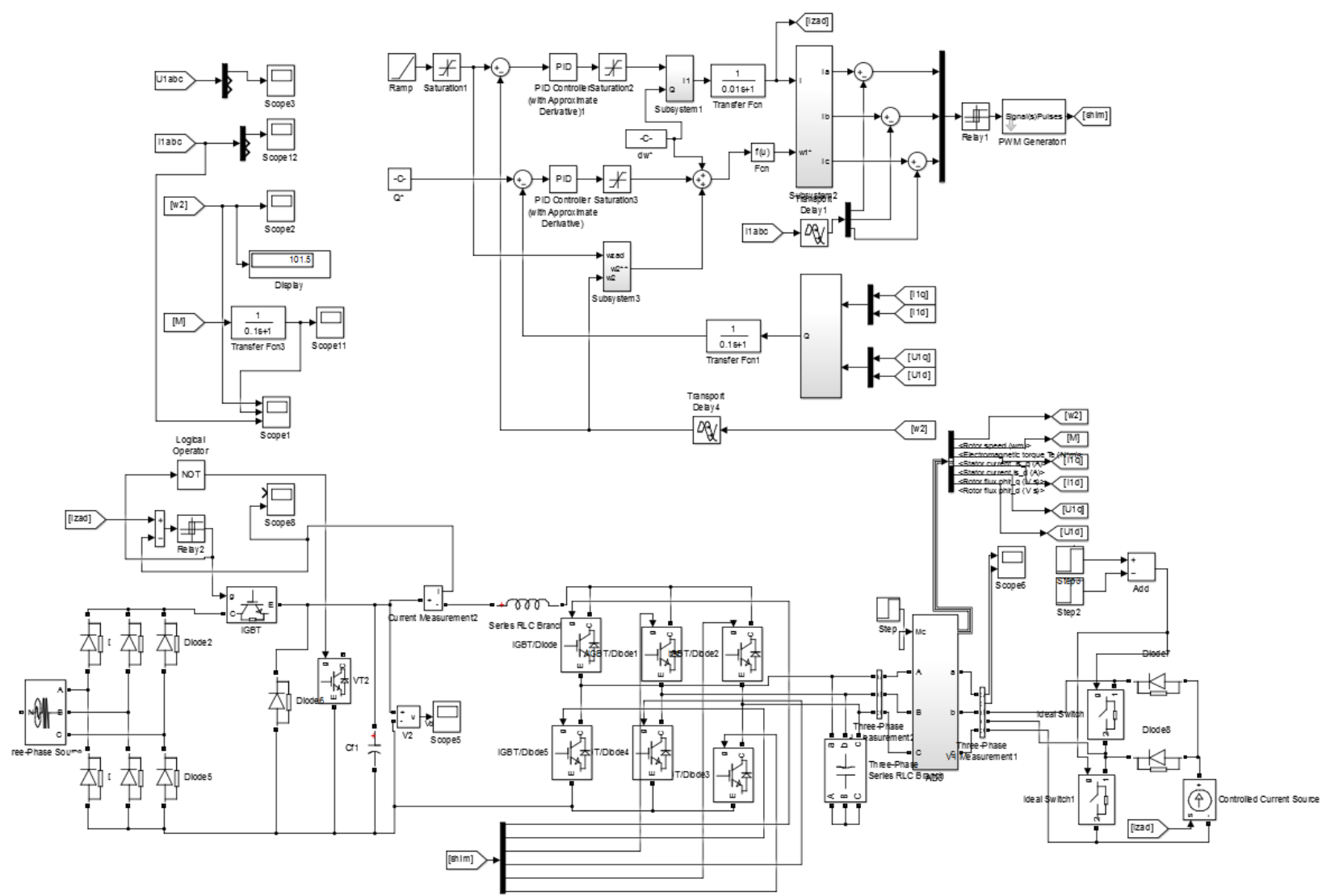

Fig. 3. Model of the synchronized asynchronous electric drive. 


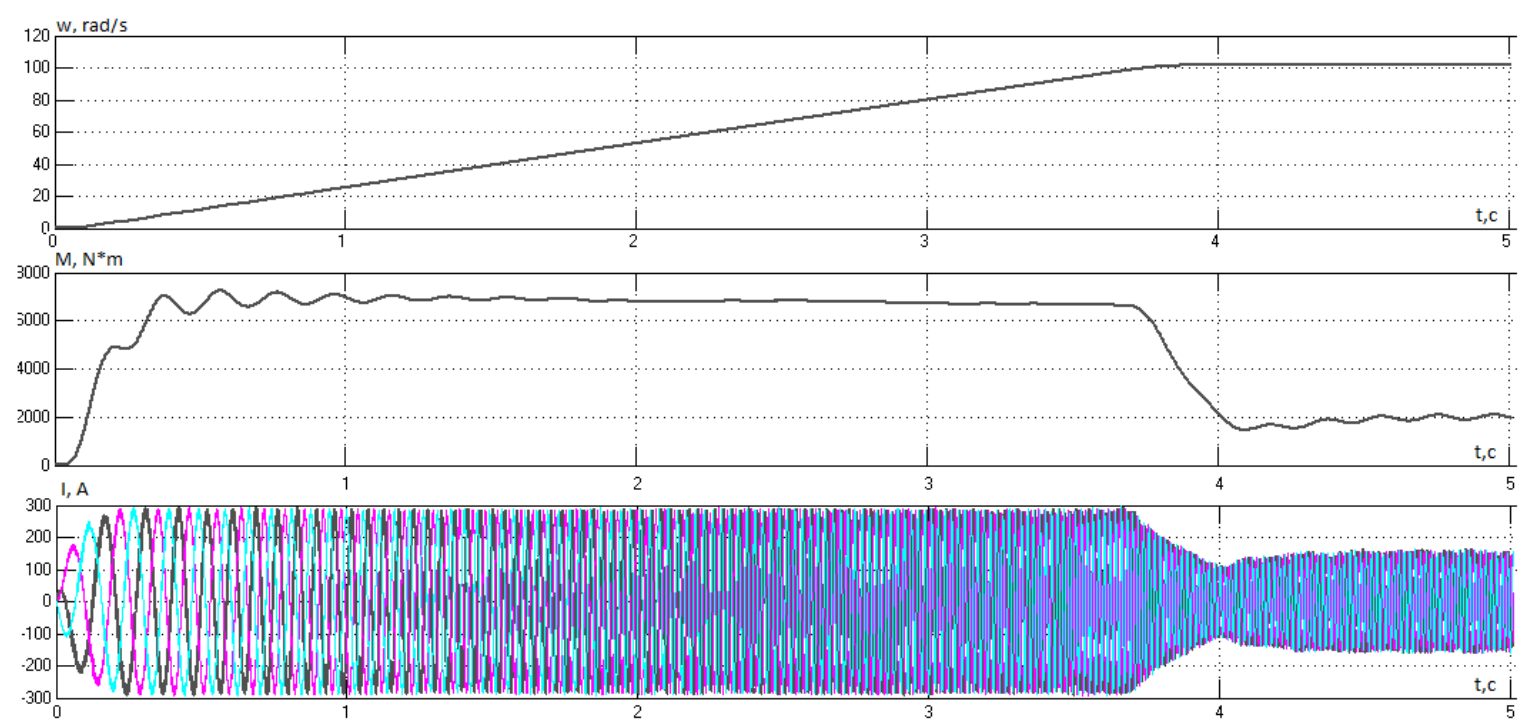

Fig. 4. Simulation results of a synchronized asynchronous electric drive.

influenced by the value of the torque angle, the prompt speed setting was corrected in the control system in order to maintain this angle constant in the start-up mode. The vector correction of variables introduced into the scalar control system allows to orient the stator current vector relative to the rotor flux-linkage vector at any moment. Thus, the starting torque is stabilized in the synchronized frequency drive control system. This allows to use this ED on mechanisms with a cyclic operation mode.

\section{Acknowledgements}

The paper was powered by research grant RFBR 19-48480001 "Development, investigation and optimization of energy-saving electrical and electrically driven automated systems for plasma, electrometal slag and induction technologies and units "

\section{References}

[1] G.G. Sokolovsky, AC electric drives with frequency control (Moscow, Academy, 2006) 272

[2] V.N. Meshcheryakov, Systems of an adjustable asynchronous electric drive for hoisting and transport mechanisms: monograph (Lipetsk, LSTU, 2005) 112

[3] Y.I. Gracheva, N.V Chernova, A.I. Fedotov, E.A. Fedotov, Local Fourier transformation application for mathematic modeling of synchronous machine valve actuator, Journal of engineering and applied sciences 11, special issue 1, 2939-2945 (2016)

[4] D. Maihöfner, I. Talavera, J. Hanson, C. Bott, Vertical reactive power flexibility through distributed energy resources for a reactive energy management, 11th IEEE Int. Conf. on Compatibility Power Electronics and Power Engineering, 100-105 (2017)
[5] V.N. Meshcheryakov, V.N. Voyekov, A vector control system of the valve electric drive on the basis of the independent inverter of tension with relay regulation of entrance current of the inverter and phase currents of the stator, Messenger YUURGU, Power series 17, 2, 48-57 (2017)

[6] A.S. Anuchin, Control systems of electric drives: textbook for higher education institutions (Moscow, MEI publishing house, 2015) 373

[7] V.N. Meshcheryakov, A.M. Bashlykov, O.V. Meshcheryakova, System of scalar frequency control of synchronized asynchronous machine with power supply of stator and rotor windings from autonomous current inverter (HTCS'2012: materials of International scientific and technical conference, Stary Oskol TNT, 2012) 50

[8] V. Mesheryakov, V. Voekov, V. Ivashkin, S. Valtchev, Designing the universal vector control system with relay current regulator principle for general purpose industrial AC motor drive control, 2016 IEEE International Power Electronics and Motion Control Conference (PEMC), Varna, Bulgaria (2016)

[9] V.N. Meshcheryakov, D.S. Sibirtsev, Frequency asynchronous electric drive with correction of phase shift between moment-forming vectors, Control systems and information technologies 2, 68, 48-57 (2017)

[10] Y.I. Gracheva, O.V. Naumov, Estimation of Power Losses in Electric Devices of the Electrotechnical Complex - International Conference on Industrial Engineering, Applications and Manufacturing (ICIEAM), 6 (2019)

[11] V.N. Meshcheryakov, P.N. Solomatin, Synchronized asynchronous electric drive with frequency control, News of HEIs, Electromechanics, 2, 51-57 (2009) 
[12] V.N. Meshcheryakov, V.V. Danilov, O.V. Meshcheryakova, D.V. Lastochkin, Patent for utility model RU, 180843, Device for control of asynchronous motor with phase rotor, publ. 03.07.2018, Byul. 19 (2018)

[13] H. Rehman, L. Xu, Alternative energy vehicles drive system: Control, flux and torque estimation, and efficiency optimization, IEEE Trans. Veh. Technol, 60, 3625-3634 (2011)

[14] V.N. Meshcheryakov, V.N. Voekov, I.V. Golovachev, Vector control system of PMSM based on self-commutated voltage inverter with relay controlled IGBT switch in DC link, 17th International Ural Conference on AC Electric Drives (ACED) - Ekaterinburg, Russia (26-30 March 2018) DOI: 10.1109/ACED.2018.8341703

[15] A. Pugachev, Efficiency increasing of induction motor scalar control systems, International Conference on Industrial Engineering, Applications and Manufacturing (ICIEM), Saint-Petersburg, Russia, 1-5 (16-19 May 2017)

[16] V.N. Meshcheryakov, V.V. Danilov, Sh.R. Khasanov, S. Valtchev, Minimization of the stator current in induction motor with defined load on the shaft by maintaining optimum absolute slip, Kazan, SES 2019, E3S Web of Conferences, 01036 (2019)

[17] Y.I. Gracheva, O.V. Fedorov, Forecasting Reliability Electrotechnical Complexes of In-Plant Electric Power Supply Taking into Account LowVoltage Electrical Apparatuses, International Conference on Industrial Engineering, Applications and Manufacturing (ICIEAM), 5 (2019)

[18] A.M. Abakumov, D.G. Randin, Research of DualMass Oscillation System with Linear Motor, International Conference on Industrial Engineering, Applications and Manufacturing (ICIEM), Sochi, Russia, 1-5 (25-27 March 2019)

[19] V.N. Meshcheryakov, D.V. Lastochkin, Z.M. Shakurova, S. Valtchev, Energy saving system of cascade variable frequency induction electric drive, SES 2019, Kazan, E3S Web of Conferences, 01037 (2019)

[20] Y.I. Gracheva, A.N. Alimova, Calculating Probability of Faultless work of Shop Nets with the Help of Coefficients of Ratio, International Russian Automation Conference (RusAutoCon), 3-6 (2019)

[21] S.G. Herman-Galkin, Virtual laboratories of semiconductor systems in the environment of Matlab-Simulink: textbook (Saint-Petersburg, Lan publishing house, 2013) 448 